\title{
Effect of ettringite morphology on the properties of expanding cement systems
}

\author{
Igor Kharchenco ${ }^{1,1}$ and Vyacheslav Alekseev ${ }^{1}$ \\ ${ }^{1}$ Moscow Build State University, 129337, Moscow, Yaroslavskoye shosse, 26, Russia
}

\begin{abstract}
The effect of the $\mathrm{pH}$ of the reaction solution on the crystallization process and the ettringite morphology is theoretically substantiated and experimentally proved. Using physical and chemical research methods, the dependence of the morphology of crystallizing ettringite on the $\mathrm{pH}$ value of the reaction solution was established. It has been established that by introducing mineral micro fillers into the composition of expanding cement, it is possible to actively influence the $\mathrm{pH}$ value, the morphology of the resulting ettringite, the expansion kinetics, and the strength of cement stone and concrete based on it. The studies of the technical properties of concrete on the basis of expanding cements of various types have shown that with the introduction of micro fillers into the concrete composition, which intensify volume expansion during hydration of cement stone at the building site or factories for the production of ready-mixed concrete, it is possible to control the kinetics and extent of expansion, expansion pressure, deformative and strength characteristics of concrete and reinforced concrete structures.
\end{abstract}

\section{Introduction}

The essential condition constraining the wide application of expanding cements and concrete based on them in building practice is the lack of an integrated approach to managing the processes of their structure formation $[1,2]$ and properties, taking into account various combinations of "external" and "internal" factors of influence $[3,4]$.

At the same time, "external" factors of influence are, first of all, temperature and humidity conditions of hardening [5], as well as conditions for limiting expansion strains [6]. The most important "internal" factors of influence, along with the number and intensity of the formation of ettringite, is its morphological structure [1, 7].

Ettringite, as a product of cement hydration, has been known for more than 130 years $[1,2]$, and its formation kinetics and stability have been the subject of research in numerous studies $[8,9]$. At the same time, in most cases, ettringite was studied as a product of the chemical reaction of calcium aluminates and sulfates in aqueous solution [9, 10]. In the scope of these studies, the influence of physical factors (temperature, humidity, pressure) $[11,12]$ affecting the solubility of the aluminate and sulfate components determining the concentration of calcium, aluminum ions and sulfates in the reaction solution was mainly

1 Corresponding author: 634586@mail.ru 
analyzed [13, 14]. It is known that the reaction of formation of ettringite develops in accordance with the equation:

$$
\begin{aligned}
& 2 \mathrm{C}_{3} \mathrm{~A}+3 \mathrm{CaSO}_{4} \times 2 \mathrm{H}_{2} \mathrm{O}+26 \mathrm{H}_{2} \mathrm{O}=3 \mathrm{CaO} \times \mathrm{Al}_{2} \mathrm{O}_{3} \times 3 \mathrm{CaSO}_{4} \times 32 \mathrm{H} 2 \mathrm{O} \\
& \mathrm{Or} \\
& 6 \mathrm{Ca}^{2+}+3 \mathrm{SO}_{4}^{2-}+2 \mathrm{Al}^{3+}+12 \mathrm{OH}^{-}+26 \mathrm{H}_{2} \mathrm{O}=3 \mathrm{CaO} \times \mathrm{Al}_{2} \mathrm{O}_{3} \times 3 \mathrm{CaSO}_{4} \times 32 \mathrm{H}_{2} \mathrm{O}
\end{aligned}
$$

One of the basic provisions of physical chemistry should be borne in mind, according to which the content of all functional groups in the reaction solution is largely determined by the activity of hydrogen ions and hydroxide [13]. Usually, the concentration of hydrogen ions $(\mathrm{H}+)$ is expressed in terms of $\mathrm{pH}$ index, which is also a measure of the concentration of hydroxide ions, since the concentration of hydrogen ions and hydroxide $(\mathrm{OH}-)^{*}(\mathrm{H}+)$ is constant in an aqueous solution [14].

During the hardening of hydraulic binders, hydration products are formed due to the interaction of ions in solution. As a rule, the hydration reaction develops under alkaline conditions at a $\mathrm{pH}$ index in the range from 10.5 to 13.0. Thus, hydroxide ions have a significant influence on the formation of hydration products. In this regard, both scientific and practical interest is the question of the influence of the concentration of $\mathrm{OH}$-ions contained in the reaction solution on the formation of ettringite and the properties of expanding cement $[15,16]$.

The results of the study of the influence of $\mathrm{pH}$ index on the formation of ettringite are presented in a limited volume $[17,18,19]$. In this case, studies were performed at $\mathrm{pH}=$ $12.5 \ldots 14.0$ by changing the concentration of $\mathrm{KOH}$ and $\mathrm{NaOH}$ in the reaction solution [10]. As a result of the study, it was established that ettringite remains in a stable state with a $\mathrm{pH}$ $\leq 13.0$. In other studies, the stability of hydration products in the $\mathrm{CaO}-\mathrm{Al}_{2} \mathrm{O}_{3}-\mathrm{CaSO}_{4}-\mathrm{H}_{2} \mathrm{O}$ system is studied in the range of $\mathrm{pH}$ index from 4.0 to 14.0 at normal temperature [17]. The authors found that ettringite exists in a stable state at $\mathrm{pH}=10.8 \ldots 12.5$. At $\mathrm{pH}>13.0$, in the structure of ettringite crystals, calcium sulphate molecules are replaced by portlandite molecules. At a pH below 10.8, ettringite decomposes to release aluminum hydroxide. However, studies are known in which ettringite exists and can form when the $\mathrm{pH}$ is below 9.0 [20].

Some inconsistency of the results of the presented studies can be explained by the fact that strongly dissociating components (acids, alkalis) presented in the reaction medium, as a result of which mutually reversible reactions may develop in the interaction of calcium, aluminum and sulfate ions, taking into account the changing solubility of the initial components. At present, there is a generally accepted opinion that the kinetics of the formation of ettringite, with other things being equal, is mainly determined by the concentration of Ca-ions in solution [19, 21].

The reason for this, in our opinion, not enough correct statement is the fact that in experimental studies, the corresponding $\mathrm{pH}$ index was established by the introduction of calcium hydroxide into the reaction medium. At the same time, with an increase in the concentration of Ca-hydroxide, the solubility of the other initial components participating in the reaction decreases. This leads to a violation of the stoichiometric ratio, which is necessary for the formation of ettringite. In addition, it is known that when $\mathrm{pH}>12.0$, insoluble calcium hydroxide molecules (more than $90 \%$ ) and only less than $5 \%$ of calcium ions are found in an aqueous solution [22]. Thus, the control of the concentration of Ca-ions in an aqueous solution is important. However, it is insufficient to be able to control the kinetics of the formation of ettringite. For this, it is necessary to take into account the level of concentration of the $\mathrm{OH}$ group, which is the most important component of the reaction medium $[11,19]$. 


\section{Materials and methods}

For the purpose of experimental verification of this statement, a complex of physical and chemical studies of ettringite was performed using X-ray phase, infrared spectral and differential thermal analyzes supplemented by studies using a scanning electron microscope with zooming from 1:3,000 to 1:10 000. Crystals of ettringite were obtained by mixing aqueous solutions of calcium hydroxide and aluminum sulfate in the stoichiometric ratio required for the formation of ettringite. The given value of $\mathrm{pH}$ in the reaction solution was established by introducing citric acid or atropine alkali, which is an alkaloid alkali of organic origin, into its composition. The $\mathrm{pH}$ value was determined by a potentiometric method using combined solid-contact electrodes of the "EST" type with an accuracy of $0.05 \ldots 0.1$. Crystallization of ettringit was carried out at $\mathrm{T}=20^{\circ} \mathrm{C}$, followed by filtration and preservation of the sediment.

The ratio of longitudinal to transverse size of the crystal was used to quantify the habit of the formed ettringite crystals.

The analysis of the study results was performed in accordance with the structural model of ettringite, which was proposed by Taylor [23, 24] (see Fig. 1).

In accordance with this model, the ettringite crystal is a prism, the chemical composition of which can be represented as $\mathrm{Ca} 6\{\mathrm{Al}(\mathrm{OH}) 6\} 2(\mathrm{SO} 4) 3 \times 25,7 \mathrm{H} 2 \mathrm{O}$. At the same time, each $\mathrm{OH}$-group is connected to two Ca-ions and one $\mathrm{Al}$-ion.

Thus, a connection is provided between $\mathrm{Al}$ and $\mathrm{Ca}$ cations through each $\mathrm{OH}$-group, strengthening the crystal structure both in the longitudinal and in the transverse direction.

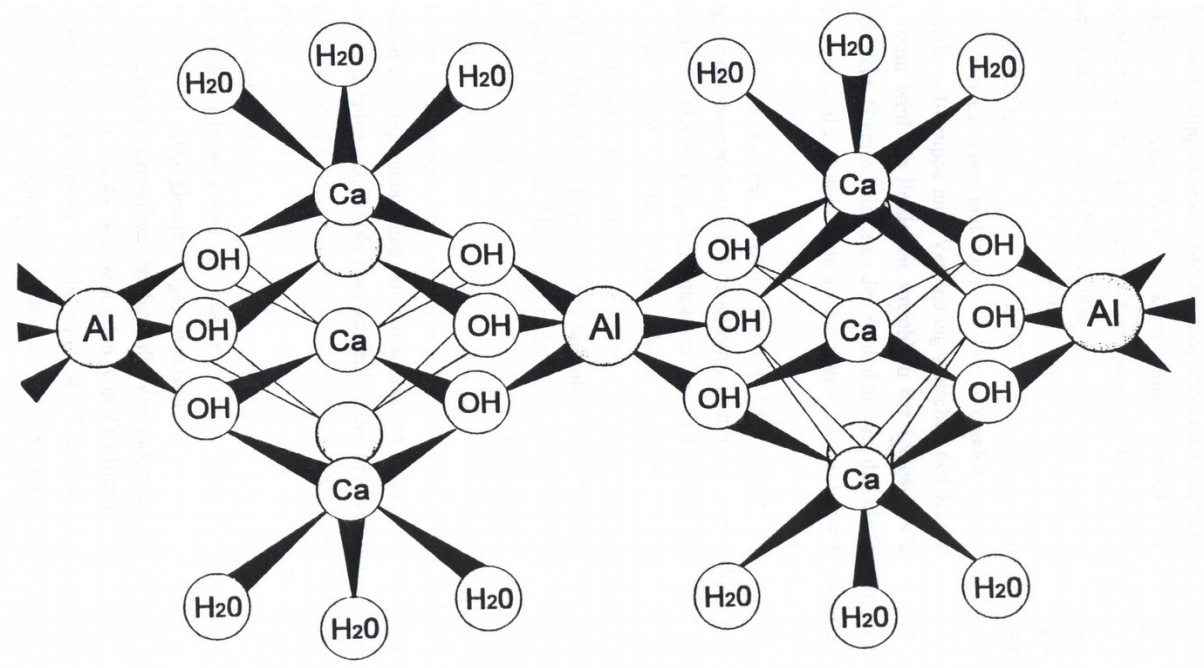

Fig. 1. The structural model of ettringite by Taylor.

Here we can conclude that ions of $\mathrm{OH}$-group play an important role in the formation of ettringite crystals, and by changing the concentration of $\mathrm{OH}$-ions in an aqueous solution, it is possible to actively and purposefully influence the crystallization process of ettringite and the formation of the corresponding crystal morphology. 


\section{Results}

As the analysis of the study results shows, in the range of $\mathrm{pH}$ index from 11.0 to 12.0, the concentration of $\mathrm{OH}$-ions has a subtle effect on the morphological structure of ettringite. Under these conditions, the classic needle-like ettringite is formed.

With an increase in $\mathrm{pH}$ index in the range from 12.0 to 12.5 , a spatially radiant form of ettringite is formed with fine developed crystals resembling the shape of fibers.

At $\mathrm{pH}$ index from 13.0 and above, ettringite is formed in the form of granular aggregates, which, according to the results of XRF, do not have reflexes characteristic for ettringite, which can be classified as X-ray amorphous or gel-like.

The formation of X-ray amorphous ettringite at $\mathrm{pH}=13.0$ and above is confirmed by the results of studies using DTA, XRF and electron microscopy.

When $\mathrm{pH}$ index varies in the range between 10.5 and 11.0, a uniform network of needlelike crystals is formed with a small degree of filling of the space with the ratio of "longitudinal-transverse" dimensions from 40 to 60 .
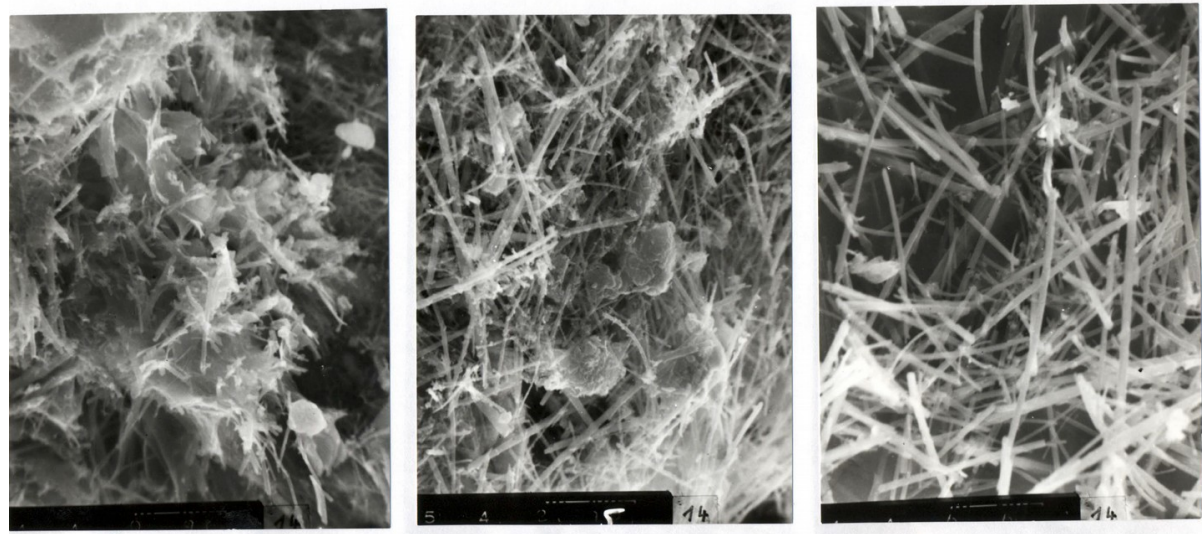

Fig. 2a. Crystals of ettringite on a scanning electron microscope (zooming 1:3000; reaction solution at $\mathrm{pH}=9 \div 10.5$ ).

With a decrease in $\mathrm{pH}$ index from 10.5 to 9.0, the "longitudinal-transverse" ratio decreases rapidly from 40 to 5 . Thus, $\mathrm{OH}$-ions should be considered as elements that play an important role in the formation of the skeleton of ettringite crystals.
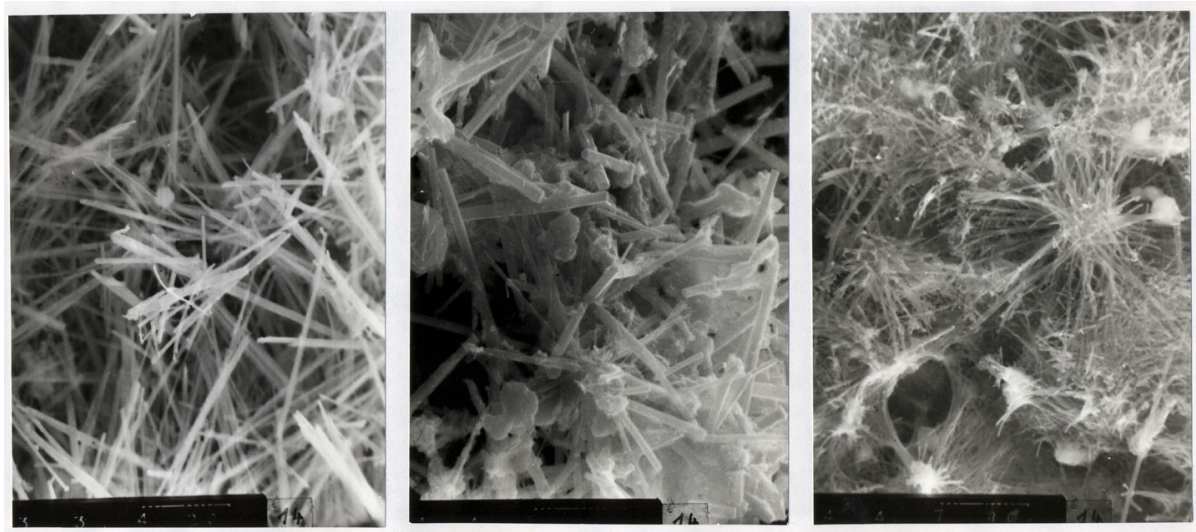

Fig 2b. Crystals of ettringite on a scanning electron microscope (zooming 1:3000; reaction solution at $\mathrm{pH}=11 \div 12$ ). 

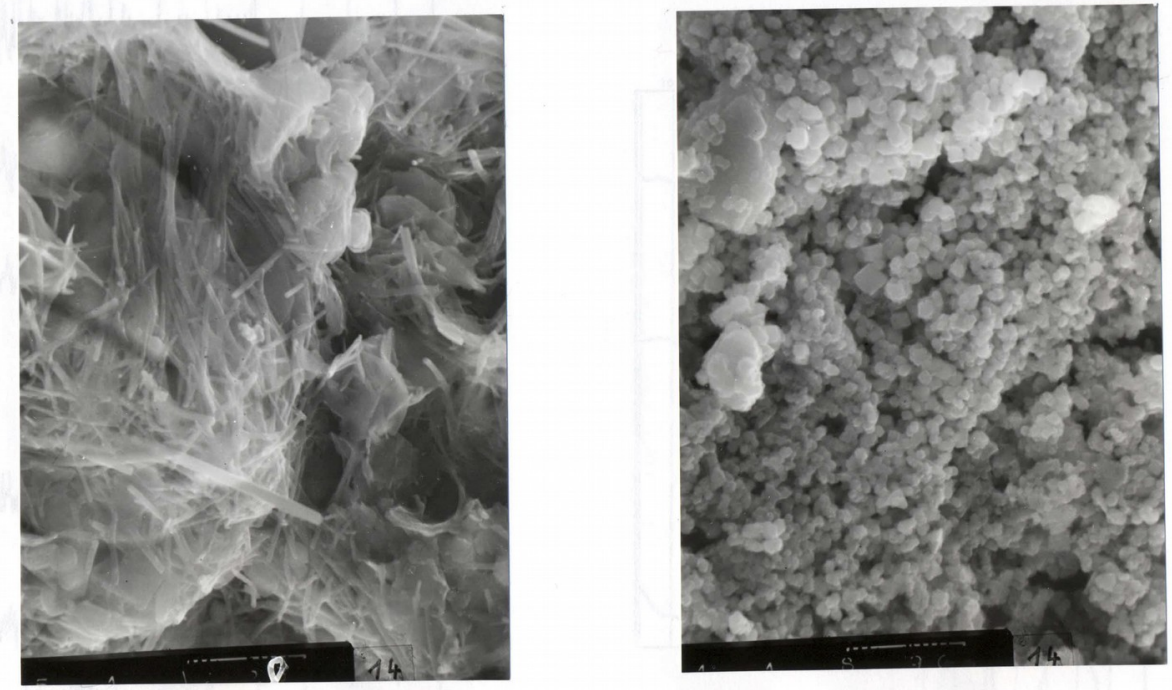

Fig 2c. Crystals of ettringit on a scanning electron microscope (zooming 1: 3000; reaction solution at $\mathrm{pH}=12.5 \div 13.0$ ).

With a low $\mathrm{pH}$ index, i.e. with the relative lack of $\mathrm{OH}$-ions in the reaction solution, despite the presence of a stoichiometrically necessary amount of aluminum ions, calcium and sulfate ions, the formation of ettringite is difficult.

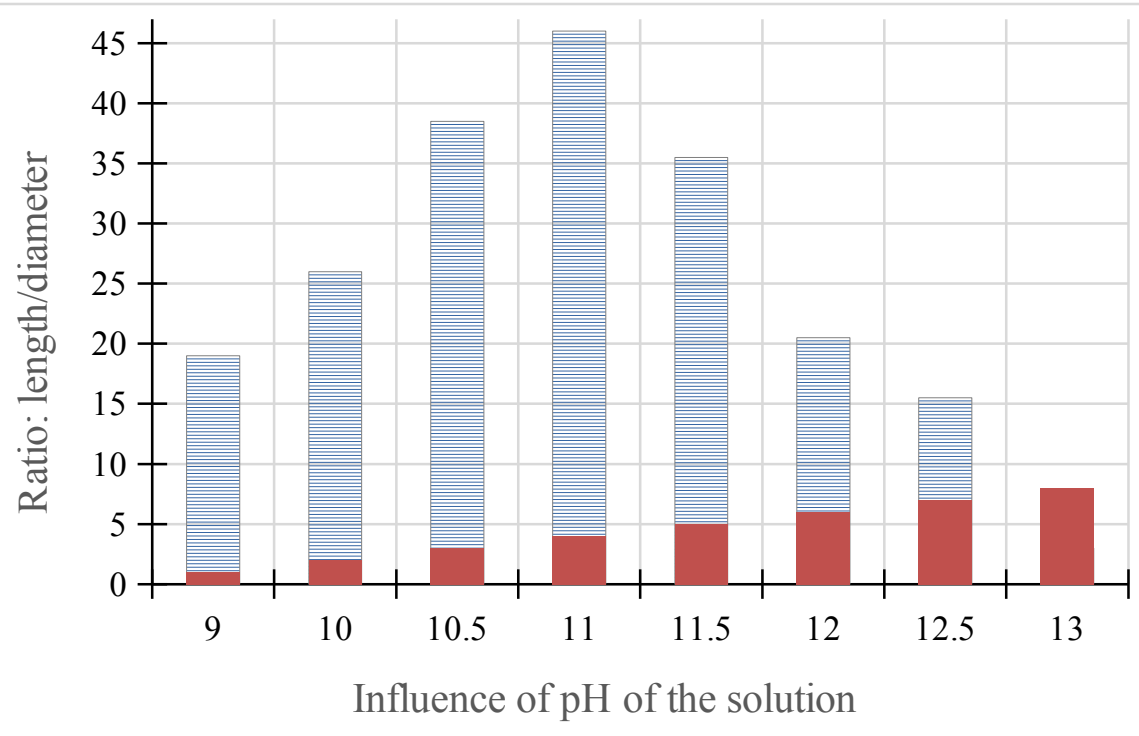

Fig. 3. Change in the habit of ettringite depending on $\mathrm{pH}$ index in the reaction solution.

From a practical point of view, this means that by controlling $\mathrm{pH}$ index at the initial stage of the development of the cement hydration process, it is possible to actively influence the kinetics of formation and morphology of ettringite and, therefore, actively influence the structure formation and properties of the expanding cement stone based on the calcium sulfoaluminate. 
In order to establish the influence of the kinetics of formation and morphology of ettringite on the expansion process and other properties of expanding cements, studies have been carried out on the basis of gypsum-alumina expanding cements (GA-EC).

Table 1. The chemical composition of the mineral micro fillers in the composition of GA-EC.

\begin{tabular}{|c|c|c|c|c|c|c|c|c|c|c|}
\hline Additives & \multicolumn{10}{|c|}{ Chemical composition, $\%$} \\
\hline & $\begin{array}{l}\mathrm{SiO} \\
2\end{array}$ & $\begin{array}{l}\mathrm{Al}_{2} \mathrm{O} \\
3\end{array}$ & $\begin{array}{l}\mathrm{Fe}_{2} \mathrm{O} \\
3\end{array}$ & $\begin{array}{l}\mathrm{Ca} \\
\mathrm{O}\end{array}$ & $\begin{array}{l}\mathrm{Mg} \\
\mathrm{O}\end{array}$ & $\begin{array}{l}\mathrm{K}_{2} \\
\mathrm{O}\end{array}$ & $\begin{array}{l}\mathrm{Na}_{2} \\
\mathrm{O}\end{array}$ & $\begin{array}{l}\mathrm{SO} \\
3\end{array}$ & $\begin{array}{l}\mathrm{Ca} \\
\mathrm{O} \\
\text { fr. }\end{array}$ & $\begin{array}{l}\mathrm{Gv} \\
100 \\
0 \\
{ }^{\circ} \mathrm{C}\end{array}$ \\
\hline $\begin{array}{l}\text { Alumina } \\
\text { cement }\end{array}$ & 0.0 & 70.3 & 2.6 & $\begin{array}{c}25 . \\
4\end{array}$ & 0.0 & 0.1 & 0,0 & 0,0 & 0,9 & 0,8 \\
\hline Gypsum & 0.1 & 0.0 & 0.0 & $\begin{array}{c}36 . \\
8\end{array}$ & 0.7 & 0.0 & 0,0 & $\begin{array}{c}50, \\
5\end{array}$ & 0,0 & 10,5 \\
\hline $\begin{array}{l}\text { Microsilic } \\
\text { a (silica } \\
\text { fume) }\end{array}$ & $\begin{array}{c}94 . \\
7\end{array}$ & 1.0 & 1.8 & 0.4 & 0.5 & - & - & - & - & 2,7 \\
\hline $\begin{array}{l}\text { White } \\
\text { hydrated } \\
\text { lime }\end{array}$ & - & 0.8 & 0.2 & $\begin{array}{c}70 . \\
3\end{array}$ & 0.0 & 0.0 & 0.0 & 0.1 & - & 28.5 \\
\hline Opaline & $\begin{array}{c}83 . \\
1 \\
\end{array}$ & 8.2 & 2.1 & 1.4 & 1.1 & - & - & - & - & 2.9 \\
\hline Chalk & $\begin{array}{c}15 . \\
5 \\
\end{array}$ & 2.2 & 1.9 & $\begin{array}{c}54 . \\
5 \\
\end{array}$ & 1.7 & - & - & - & - & 24.2 \\
\hline $\begin{array}{l}\text { Silica } \\
\text { sand }\end{array}$ & $\begin{array}{c}94 . \\
0\end{array}$ & 2.0 & 0.7 & 1.2 & 1.3 & 0.2 & 0.1 & - & - & 2.1 \\
\hline
\end{tabular}

When choosing GA-EC as an object for studying the properties and processes of structure formation of EC, it was assumed that all samples have the same potential for the formation of an equal amount of ettringite, which is provided by the stoichiometric ratio of the initial components necessary for its formation.

In addition, when applying GA-EC to the study of the expansion process, such an important factor for the technology of expanding cements is recorded - the amount of formed ettringite, which significantly affects the size and expansion kinetics.

When conducting experimental studies, by introducing various mineral micro fillers into the composition of GA-EC, the content of OH-ions in the reaction solution was purposefully changed, which, accordingly, influenced the kinetics of ettringite formation, its morphology, and properties of expanding cement.

Expanding cement was made by 60 -minute homogenization of alumina cement and ground gypsum in the stoichiometric ratio necessary for the formation of ettringite. Chemically active silica "SF", pure calcium hydroxide $(\mathrm{CH})$ and ground silica sand (S) were used as the mineral micro filler. Before introducing into the composition of GA-EC, the initial mineral micro fillers were mixed in a ball mill and introduced in the amount of $6 \%$. Introduction into the composition of GA-EC of active silica fume "SF" allows, due to the pozzolanic property, reducing the content of $\mathrm{Ca}$ - and $\mathrm{OH}$-ions in the reaction solution. Calcium hydroxide on the contrary, significantly increases the content of hydroxide ions during the hydration process. Ground silica sand contains silicon dioxide only in a passive form and does not affect the development of a chemical reaction during hydration and hardening of GA-EC. 


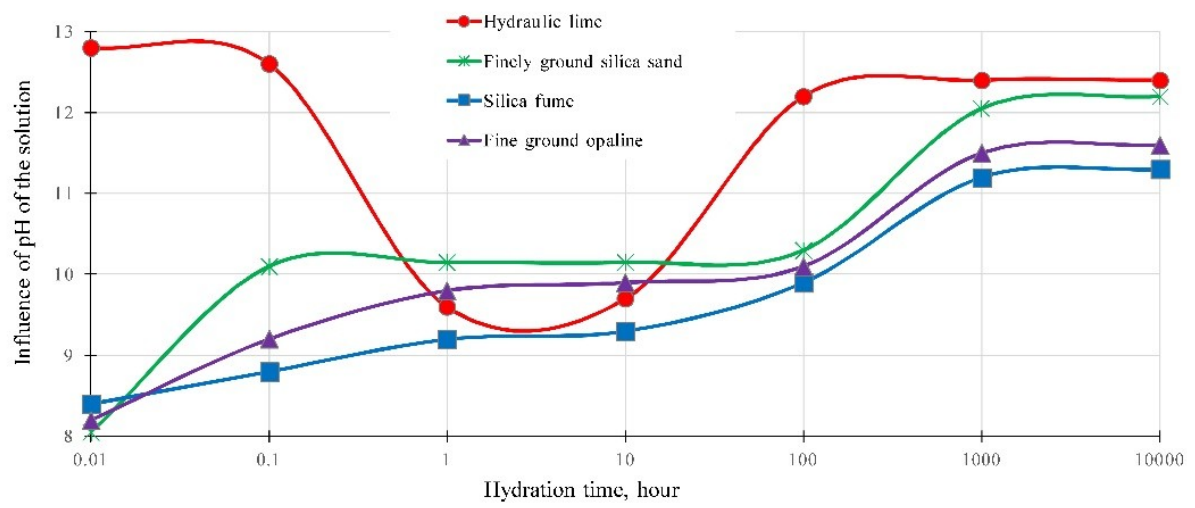

Fig. 4. Changes in $\mathrm{pH}$ index during the development of the hydration process of GA-EC with various mineral micro fillers.

During the development of the hydration process up to 28 days, $\mathrm{pH}$ index and the content of ions in the pore solution were determined. After the completion of active structure formation at the age of hardening of 28 days, the liquid phase was pressed out from the pores of the cement stone in accordance with the ASTM method [24]. At the same time, with the use of physical and chemical methods of study, the products of hydration were determined, the pore structure, the magnitude of expansion, and the kinetics of the strength development of expanding cements were studied.

The studies have shown that, depending on the type of mineral micro filler introduced into GA-EC, $\mathrm{pH}$ indexes of the pore solution significantly differ from the beginning of the mixing to 24 hours (Fig. 4).

When using calcium hydroxide, $\mathrm{pH}$ index in the composition of GA-EC varies from 12.5 to 12.8 . With the introduction of amorphous silica (SF), the $\mathrm{pH}$ index varies from 8.3 to 8.5. With the introduction of calcium hydroxide $(\mathrm{CH})$ in the composition of GA-EC, an intensive drop in the $\mathrm{pH}$ index to 9.5 follows in the first 20 minutes after mixing, in contrast to the expanding cements containing "SF".

Of particular interest are the properties of GA-EC containing " $\mathrm{CH}$ " in their composition, which showed an extreme difference between the value of expansion and compressive strength (Fig. 5 and Fig. 6).

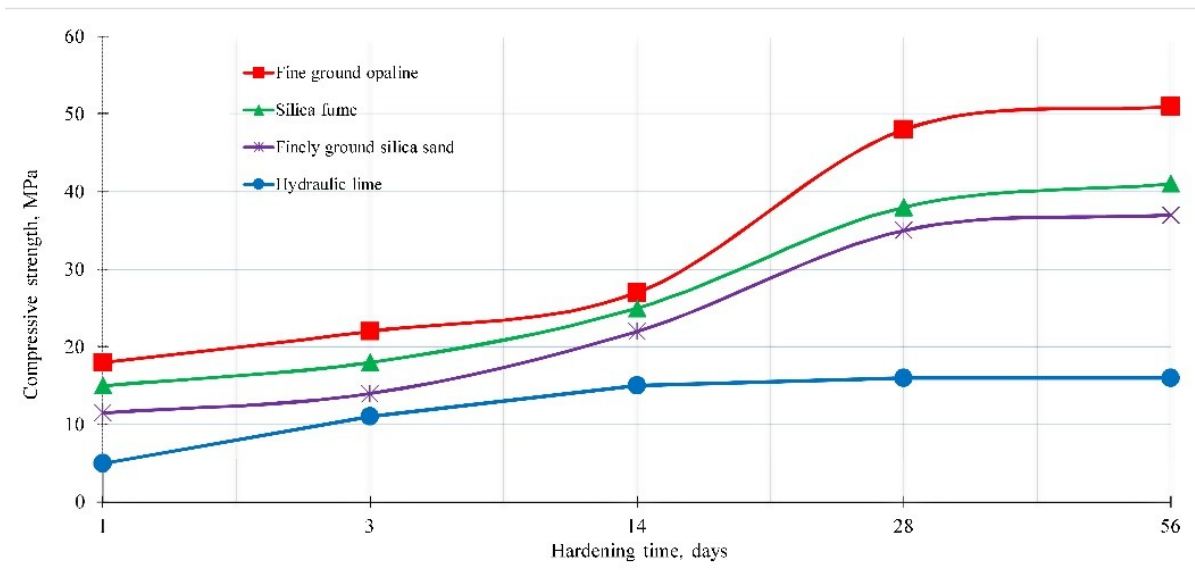

Fig. 5. The value of the compressive strength of GA-EC with various mineral micro fillers. 


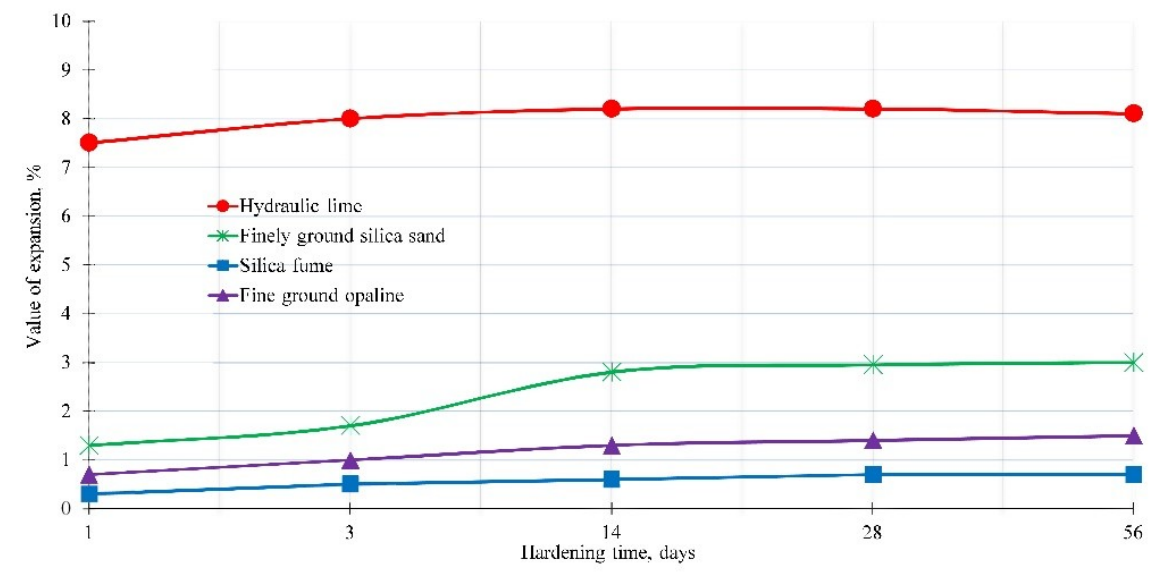

Fig. 6. Kinetics of the expansion of GA-EC with various mineral micro fillers.

Straight after mixing, $\mathrm{pH}$ index was comparable, it rapidly decreased during the first 6 minutes with the use of "CH" from 12.5 to 9.7 and remained constant at this level for up to 72 hours.

\section{Discussion}

The analysis of hydration products showed that ettringite during this period was formed with constant intensity, and after 3 days its amount reached $85 \%$.

This phenomenon can be explained by the formation of so-called shielding membranes on the surface of cement particles, which prevent further hydration process and at the same time cause a decrease in the concentration of $\mathrm{OH}$-ions in the pore solution.

The study of cement slurry, cement paste, and later cement stone at different stages of the development of the hydration process of GA-EC showed that the shielding layer consists mainly of fine-crystalline ettringite with a "longitudinal - transverse" ratio up to 15 or less to the formation of a dense or "gel-like" form, which are topochemically formed on the surface of clinker materials under the influence of high concentrations of $\mathrm{Ca}$ - and $\mathrm{OH}$ ions in the solution (Fig. 3).

The impermeability and thickness of the shielding membrane of ettringite on the surface of cement grains with the addition of calcium hydroxide is higher than with GA-EC with amorphous silica, since the concentration of $\mathrm{OH}$-ions in the reaction medium is lower. With the further development of the hydration process, ettringite is formed in the intermediate space between non-hydrated clinker materials and the shielding membrane. In this regard, there is a pressure of crystallization on the inner side of the shielding membrane. Moreover, the stress state of the shielding membrane increases due to the difference in the concentrations of hydration products in the inner and outer areas. As the hydration process develops, the space between the inner surface of the shielding membrane and non-hydrated clinker materials is compacted, tensile stresses increase, which leads to their destruction.

After the destruction of the shielding membranes, the process of hydration of cement clinker gets a new development, as can be seen from the intensive increase in $\mathrm{pH}$ index (Fig. 4). During this period, an intensive development of the expansion process is observed, the value of which reaches $8 \%$ of the volume increase (Fig. 6). Due to the fact that the hydration process was accompanied by intensive expansion, the compressive strength had relatively low indicators (Fig. 5). 
The studies of the hydration process of GA-EC with the addition of silica fume, which contain silicon oxide in a chemically active form, have shown that, along with ettringite, $\mathrm{CSH}$ phases also appear already after the first minutes of hydration. Immediately after mixing with water, both GA-EC have a $\mathrm{pH}$ index from 8.1 to 8.3. This figure is comparable to the GA-EC with the addition of ground silica sand. The $\mathrm{pH}$ index is consistently increased during the first 60 minutes, along with an increase in the amount of ettringite, which forms in the form of fine crystals with a "length-diameter" ratio from 30 to 40 . The intensity of changes in $\mathrm{pH}$ index depends on the chemical activity of additives containing $\mathrm{SiO}$. The higher the activity, the slower the $\mathrm{pH}$ changes. Ettringite crystallizes from the solution and is evenly distributed throughout the structure of the cement stone. On the surface of cement clinker particles, a relatively dense screening layer is formed, which consists of ettringite, CSH-phase, and other gel-like phases, and has a low permeability for aqueous solutions, as well as from other hydration products. On this basis, the hydration process proceeds evenly and consistently with an almost constant $\mathrm{pH}$ index for 3 days. The formation of fine crystalline ettringite in a pore volume filled with water causes hydrostatic pressure, which is the reason for the increase in volume to $0.7 \%$ with GA-EC with the addition of ground silica. With the development of the hydration process of GA-EC with the addition of silica sand (S), which is chemically passive under normal conditions, a loose separating layer forms on the surface of cement clinker particles, which practically consists of needle-like ettringite, which has a very high permeability for aqueous solution and hydration products. Due to this, $\mathrm{pH}$ index rises intensively during the first 4 minutes, and the further hydration process proceeds evenly and consistently with a practically constant $\mathrm{pH}$ of 10.5 .

The formation of ettringite in the pores also causes hydrostatic pressure, along with the crystallization pressure. Both of these factors are the main reasons for a fairly intensive increase in volume (about 3\% in 7 days) when hardening expanding cement with finely ground silica sand. The maximum increase in volume up to $1.9 \%$ was shown by GA-EC with fine ground silica sand as a micro filler. Further slow expansion up to $3.9 \%$ for 2 months in the case of expanding cement with the addition of fine ground silica sand led to the formation of microcracks on the sample surface. The formation of cracks caused a significant decrease in strength, which led to self-destruction of the cement stone.

The significant effect of various mineral micro fillers on the processes of hydration and structure formation is manifested in the different influence on the $\mathrm{pH}$ value in the initial period of the hydration process after the introduction of mixing water. To control the hardening process of expanding cements based on calcium sulfoaluminate and the properties of expanding cements, it is important to establish at what values of $\mathrm{pH}$ the ettringite crystals seeds are formed, and how they develop with the further development of the hydration process of the cement stone.

\section{Conclusion}

1. It is established that the $\mathrm{pH}$ value of the reaction solution has a significant influence on the crystallization process and the morphology of ettringite.

2. Based on the analysis of the results of experimental studies, the dependence of the morphology of crystallizing ettringite on the $\mathrm{pH}$ value of the reaction solution was established.

3. By introducing mineral micro fillers into the composition of the expanding cement, it is possible to actively influence the $\mathrm{pH}$ value, the morphology of the resulting ettringite, the expansion kinetics, and the strength of the cement stone. 


\section{References}

1. A. Guttmann, Verfahren zur Herstellung schwindfreien Betons (Deutschland, 1920)

2. A. Bakhrakh, A. Solodov, O. Larsen, V. Naruts, O. Aleksandrova, B. Bulgakov, MATEC Web of Conferences "International Science Conference SPbWOSCE-2016 "SMART City", 03016 (2017) DOI:10.1051/matecconf/201710603016

3. A. Bloodworth, J. Su, Underground Space 3(2), 87-108 (2018) DOI/10.1016/j.undsp.2017.12.001

4. I. Galobardes, S.H. Cavalaro, C.I. Goodier, S.Austin, Á. Rueda, Construction and Building Materials 79, 357-369 (2015) DOI/10.1016/j.conbuildmat.2014.12.038

5. Q. Cao, Z.J. Ma, Construction and Building Materials 75, 450-457 (2015) DOI/10.1016/j.conbuildmat.2014.11.045

6. H. Yu, L. Wu, W. V. Liu, Y. Pourrahimian, Journal of Rock Mechanics and Geotechnical Engineering 10(2), 212-221 (2018) DOI/10.1016/j.jrmge.2017.12.001

7. I. Odler, I. Jawed, Materials science of concrete II. American Ceramic Society: Westerville, 221-248 (1991)

8. I. Chartschenko, J. Stark, Wiss. Zeitschr. Hochsch. Arch. Bauwesen Weimar 39/3, $163-$ $171(1993)$

9. V.V. Mikhaylov, S.L. Litver, Expanding cements, straining cements, and self-stressed reinforced concrete structures (Stroyizdat, Moscow, 1974)

10. I. Odler, I. Jawed, Materials science of concrete II. American Ceramic Society: Westerville, 221-248 (1991)

11. I.J. Chartschenko, K. Volke, J. Stark, 10th Intern. Coal Ash Symposium 6, 142-154 (1993)

12. V.A. Alekseev, Yu.M. Bazhenov, S.I. Bazhenova, O.Yu. Bazhenova, N.A. Golovashchenko, N.S. Mironchuk, Bulletin of construction equipment 5(1005), 18-19 (2018)

13. H. Choi, H. Choi, M. Lim, T. Noguchi, R. Kitagaki, Construction and Building Materials 75, 266-274 (2015) DOI/10.1016/j.conbuildmat.2014.11.003

14. I. Charschenko, J. Stark, Second CANMET/ACI Intern. Symposium of Advances in Concrete Technology, 62-71 (1999)

15. A. Adamtsevich, A. Pustovgar, Applied Mechanics and Materials 725-726, 487-492 (2015) DOI/10.4028/www.scientific.net/AMM.725-726.487.

16. I. Chartschenko, Theoretische Grundlagen zur Anwendung von Quellzementen in der Baupraxis (Habilitation. BRD, Weimar, 1995) 
17. T. Apih, G. Lahajnar, A. Sepe, R. Blinc, F. Milia, R. Cvelbar, I. Emri, B.V Gusev, L.A Titova, Cement and Concrete Research 31(2), 263-269 (2001) DOI:10.1016/S0008$\underline{8846(00) 00460-9}$

18. P. Carballosa, J.L. García Calvo, D. Revuelta, Construction and Building Materials 15(93), 223-229 (2015) DOI/10.1016/j.conbuildmat.2015.05.113

19. V.A. Alekseev, Yu.M. Bazhenov, S.I. Bazhenova, O.Yu. Bazhenova, R.S. Bisembaev, N.S. Mironchuk, Bulletin of construction equipment 8(1008), 61-63 (2018)

20. M. Ghahremannejad, M. Mahdavi, A. Emami Saleh, S. Abhaee, A. Abolmaali, Case Studies in Construction Materials 9, e00182 (2018) DOI/10.1016/j.cscm.2018.e00182

21. M. Wyrzykowski, G. Terrasi, P. Lura, Cement and Concrete Research 107, 275-283 (2018) DOI/10.1016/j.cemconres.2018.02.018

22. J.L. García Calvo, D. Revuelta, P. Carballosa, J. P. Gutiérrez, Construction and Building Materials 136, 277-285 (2017) DOI/10.1016/j.conbuildmat.2017.01.039

23. J. Chen, J. Thomas, H. Taylor, H. Jennings, Cement and Concrete Research 34(9), 1499-1519 (2004) DOI: 10.1016/j.cemconres.2004.04.034

24. H. Taylor, C. Famy, K. Scrivener, Cement and Concrete Research 31(5), 683-693 (2001) DOI 10.1016/S0008-8846(01)00466-5 